\title{
Convection-Driven Melting near the Grounding Lines of Ice Shelves and Tidewater Glaciers
}

\author{
ADRIAN JENKINS \\ British Antarctic Survey, Natural Environment Research Council, Cambridge, United Kingdom
}

(Manuscript received 5 January 2011, in final form 12 May 2011)

\begin{abstract}
Subglacial meltwater draining along the bed of fast-flowing, marine-terminating glaciers emerges at the grounding line, where the ice either goes afloat to form an ice shelf or terminates in a calving face. The input of freshwater to the ocean provides a source of buoyancy and drives convective motion alongside the ice-ocean interface. This process is modeled using the theory of buoyant plumes that has previously been applied to the study of the larger-scale circulation beneath ice shelves. The plume grows through entrainment of ocean waters, and the heat brought into the plume as a result drives melting at the ice-ocean interface. The equations are nondimensionalized by using scales appropriate for the region where the subglacial drainage, rather than the subsequent addition of meltwater, supplies the majority of the buoyancy forcing. It is found that the melt rate within this region can be approximated reasonably well by a function that is linear in ocean temperature, has a cube root dependence on the flux of subglacial meltwater, and has a complex dependency on the slope of the ice-ocean interface. The model is used to investigate variability in melting induced by changes in both ocean temperature and subglacial discharge for a number of realistic examples of ice shelves and tidewater glaciers. The results show how warming ocean waters and increasing subglacial drainage both generate increases in melting near the grounding line.
\end{abstract}

\section{Introduction}

The mass balance of ice sheets, ice caps, and glaciers that have marine termini is at least partially determined by the direct interaction between ice and ocean. The area over which that interaction occurs might include the base and front of a floating extension of the grounded ice, called an ice shelf, or could be limited to the submerged portion of a near-vertical ice wall terminating a tidewater glacier that is too thick to float free of its bed. In either case, a grounding line can be defined that marks the downstream limit of grounded ice and therefore represents the inland limit of an ice shelf or the seaward limit of a tidewater glacier. This paper considers some of the processes that determine the melt rate of the ice immediately downstream of the grounding line, whether that is a quasivertical ice face or the quasi-horizontal base of an ice shelf.

Because the grounding line marks the boundary between ice that has made most but not all (Jenkins and

Corresponding author address: Adrian Jenkins, British Antarctic Survey, High Cross, Madingley Road, Cambridge CB3 0ET, United Kingdom.

E-mail: ajen@bas.ac.uk
Holland 2007) of its contribution to sea level rise and ice that has yet to displace its full weight of water, understanding the processes that govern its location is seen as critical to a quantitative assessment of the future sea level contribution of the earth's ice masses. Hughes (1973) suggested increased melting at grounding lines as a possible mechanism by which the marine-based West Antarctic Ice Sheet could be destabilized, and several other authors have echoed this view: most recently, Schoof (2007) and Pollard and DeConto (2009). Inland movement of the grounding line of Pine Island Glacier was observed by Rignot (1998), and the accumulating evidence of rapid change on this and neighboring glaciers (Joughin et al. 2003; Shepherd et al. 2004; Rignot 2008; Wingham et al. 2009) is suggestive of an inland response to oceanic forcing of the ice shelves. Similarly, D. M. Holland et al. (2008) demonstrate an oceanic trigger for thinning and breakup of the floating tongue of Jakobshavn Isbræ that was followed by rapid acceleration of the grounded glacier (Joughin et al. 2004). Motyka et al. (2003) argued that most of the seasonal fluctuation in the position of the calving front of LeConte Glacier, an Alaskan tidewater glacier, was a direct result of changes in subsurface melting of the front. 
Most estimates of melting near the grounding line of ice shelves have been based on observations of ice flux and an assumption of steady state, such that the calculated melting or freezing and known surface ablation or accumulation balance the convergence or divergence of the ice flux. Results suggest melt rates ranging from a few meters to a few tens of meters per year with maxima either at the grounding line or a short distance downstream (Jenkins and Doake 1991; Rignot and Jacobs 2002; Joughin and Padman 2003; Jenkins et al. 2006). Melting of the vertical calving front of a tidewater glacier is more difficult to observe. Motyka et al. (2003) inferred the net input of meltwater to the ocean from observations of water properties in the fjord in front of LeConte Glacier and concluded that the ice face was melting at over $10 \mathrm{~m}_{\text {day }}{ }^{-1}$.

Models of ocean circulation beneath ice shelves can capture the broad-scale features of the buoyancy-driven overturning circulation and reproduce the observed distribution of melting and freezing beneath ice shelves, including the peak in melting near the grounding line (Hellmer and Olbers 1989; Jenkins 1991; Grosfeld et al. 1997; Beckmann et al. 1999; Jenkins and Holland 2002). However, resolving all the processes that operate at the grounding line is generally beyond the capabilities of most ocean circulation models. No model with a structured vertical grid can cope with the approach to zero water column thickness, so the grounding line is typically represented as a vertical rock wall that might be many tens of meters high.

A common assumption is that the only source of buoyancy that acts to stratify the water column and drive the overturning circulation within the sub-ice cavity is the generation of meltwater at the ice-ocean interface. However, in the key regions where fast-flowing outlet glaciers either discharge into ice shelves or terminate in fjords there will be a flow of freshwater draining across the grounding line from the glacier bed. Rapid ice flow is almost always associated with basal sliding, which is either lubricated by water at the ice-rock interface or promoted by the deformation of water-saturated sediments beneath the glacier. For polar glaciers the water is generated at the bed by a combination of geothermal and frictional heating, whereas for temperate glaciers the supply is augmented by the drainage of surface meltwater and rain through the glacier to its bed. When this water emerges at the grounding line, it provides buoyancy forcing for the overturning circulation in addition to that provided by melting at the ice-ocean interface, and the effect of this additional forcing on the melt rate immediately downstream of the grounding line is the main focus of what follows.

This study uses a simple one-dimensional model based on the theory of buoyant plumes, illustrated conceptually a

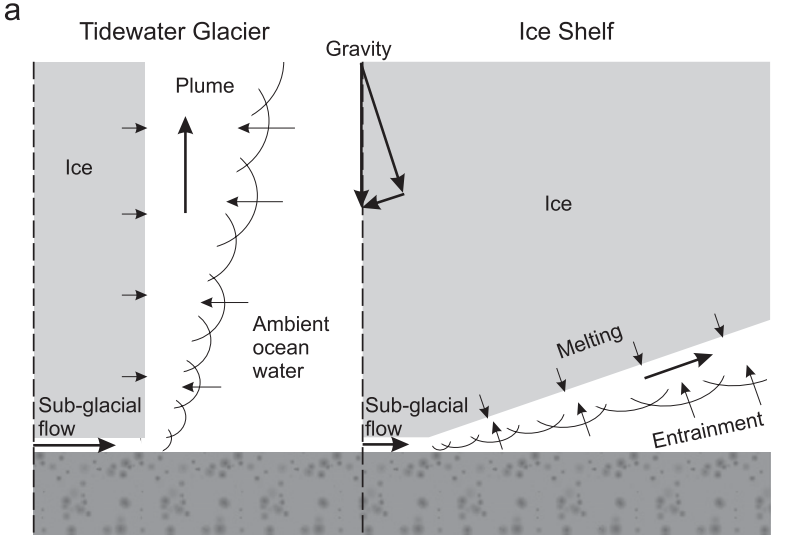

b
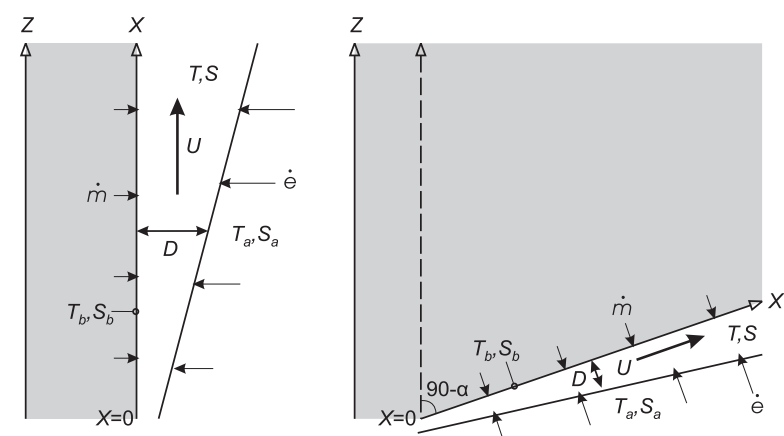

FIG. 1. (a) Conceptual picture of a buoyant plume originating from an outflow of freshwater at the grounding line of an ice shelf or tidewater glacier and (b) schematic picture of the numerical representation of (a) with key variables defined. The plume rises up the ice face, entraining seawater at it goes. The entrained seawater supplies the heat that drives melting of the ice face, and the meltwater thus derived adds to the buoyancy of the plume. Close to the grounding line, the majority of the freshwater carried within the plume will be supplied by the subglacial flow, although with sufficient downstream evolution the freshwater supplied by melting will dominate.

in Fig. 1. The theory was originally developed by Morton et al. (1956) to study convection driven by point sources of buoyancy and was subsequently applied by Ellison and Turner (1959) in slightly modified form to the case where the buoyancy-driven flow is constrained to follow a solid boundary. The key feature of all plumes is that their volume flux grows with height through the entrainment of fluid from the surroundings. MacAyeal (1985) pioneered the application of the concept to the large-scale circulation beneath ice shelves, where the plume follows a reactive boundary that melts in response to the entrainment of warm ocean water into the plume. Melting of the ice shelf base acts as a distributed source of buoyancy that can be much larger than the initial buoyancy source. For the case where there is no initial source of buoyancy, the early development of such a flow, from 
an initial sheared laminar boundary layer to a fully turbulent, entraining plume, was discussed by Wells and Worster (2008) for the case of thermal convection against a vertical heated plate. The model used here is, however, analogous to that of MacAyeal (1985), in that the plume is initiated by a meltwater flow that is assumed to be fully turbulent at its source. Although the melting of the boundary along which it flows modifies the plume buoyancy, the focus on the region close to the grounding line where the initial source of buoyancy remains a significant driver of the flow means that solutions are more analogous to those of Morton et al. (1956) and Ellison and Turner (1959).

The study has been motivated by a series of recent observations suggesting that freshwater discharge at grounding lines can be highly variable and can greatly enhance ice-ocean heat transfer over that estimated for purely melt-driven convection. Laser-altimeter data have revealed an active hydrological system beneath the Antarctic ice sheet with water moving from one subglacial lake to another (Smith et al. 2009) and periodically draining across grounding lines (Fricker et al. 2007; Stearns et al. 2008). Surface meltwater is known to drain to the bed of the Greenland Ice Sheet, imparting a seasonal variability to the motion of ice in the ablation zone (Zwally et al. 2002; Das et al. 2008; Joughin et al. 2008), and at least some of this meltwater eventually reaches the grounding lines of the tidewater glaciers and upwells at the calving fronts (Chu et al. 2009). Finally, Motyka et al. (2003) found that they could not account for the extreme melting of LeConte Glacier using conventional parameterizations of ice-ocean heat transfer and argued that convection driven by the discharge of subglacial meltwater must be enhancing the heat transfer.

The model presented in this paper is intended to account for all observations of melting near grounding lines within the context of a single theory, where the only difference from earlier applications is that the dominant source of buoyancy is defined by the initial conditions rather than the subsequent evolution of the plume. The model equations are those used by Jenkins (1991), nondimensionalized by using scales appropriate to the region where the initial flux of meltwater is the dominant source of buoyancy. The model is used to investigate the sensitivity of this convection-driven melting to grounding line geometry, seawater temperature, and the flux of freshwater across the grounding line. The aims of this study are to quantify the melt rate in the region dominated by freshwater discharge, determine the factors that control the size of that region, and understand the impact of seasonal and interannual variability in the supply of freshwater at the grounding line on melting beneath ice shelves and at the calving fronts of tidewater glaciers.
The mathematical formulation of the model is presented in the next section, followed by a discussion of the main findings and applications of the model to specific examples of ice shelves and tidewater glaciers. The results and their implications are summarized in the concluding section.

\section{The model}

This study uses the model of Jenkins (1991), in which the evolution of a buoyant, meltwater-laden plume beneath an ice shelf (Fig. 1a) is described by four ordinary differential equations. The prognostic variables are the plume thickness $D$, speed $U$, temperature $T$, and salinity $S$ (Fig. 1b). The model is steady in time, uniform in the across-flow direction, and depth-integrated, leaving the along-track distance $X$ as the only independent variable. The four equations conserve the fluxes of mass, momentum, heat, and salt,

$$
\begin{aligned}
\frac{d}{d X}(D U) & =\dot{e}+\dot{m} \\
\frac{d}{d X}\left(D U^{2}\right) & =D\left(\frac{\rho_{a}-\rho}{\rho_{0}}\right) g \sin \alpha-C_{d} U^{2}, \\
\frac{d}{d X}(D U T) & =\dot{e} T_{a}+\dot{m} T_{b}-C_{d}^{1 / 2} U \Gamma_{T}\left(T-T_{b}\right),
\end{aligned}
$$

$$
\frac{d}{d X}(D U S)=\dot{e} S_{a}+\dot{m} S_{b}-C_{d}^{1 / 2} U \Gamma_{S}\left(S-S_{b}\right),
$$

where $\alpha$ is the angle of the ice shelf base from the horizontal, $\dot{m}$ is the melt rate, and the subscripts indicate conditions in the possibly nonuniform ambient water column $a$ and conditions at the ice-ocean interface $b$ (Fig. 1b). The model is closed using a constant drag coefficient $C_{d}$; a linear equation of state,

$$
\rho=\rho_{0}\left[1+\beta_{S}\left(S-S_{0}\right)-\beta_{T}\left(T-T_{0}\right)\right]
$$

an expression that defines the entrainment rate as a linear function of the plume velocity and the sine of the interface slope,

$$
\dot{e}=E_{0} U \sin \alpha
$$

and three equations describing the balance of heat and salt at the ice-ocean interface and the liquidus condition that must hold there,

$$
\begin{aligned}
\dot{m} L_{i}+\dot{m} c_{i}\left(T_{b}-T_{i}\right) & =c C_{d}^{1 / 2} U \Gamma_{T}\left(T-T_{b}\right), \\
\dot{m}\left(S_{b}-S_{i}\right) & =C_{d}^{1 / 2} U \Gamma_{S}\left(S-S_{b}\right), \text { and }
\end{aligned}
$$




$$
T_{b}=\lambda_{1} S_{b}+\lambda_{2}+\lambda_{3} Z_{b},
$$

where $c$ is specific heat capacity, $L$ latent heat of fusion, and the subscript $i$ indicates ice properties. The second term on the left-hand side of (7) represents the heat conducted into the ice shelf; is derived by considering steady-state, one-dimensional advection and diffusion perpendicular to the melting interface; and is applicable for Péclet numbers greater than about 5 (Holland and Jenkins 1999). Equation (9) is a linearization of the liquidus relationship that facilitates algebraic solution of (7)-(9). The last term gives the dependence of the freezing point on the depth of the ice shelf base $Z_{b}$. Jenkins (1991) used expressions for the thermal and haline Stanton numbers, $C_{d}^{1 / 2} \Gamma_{T}$ and $C_{d}^{1 / 2} \Gamma_{S}$, that were derived from laboratory studies of boundary layers adjacent to hydraulically smooth surfaces (Kader and Yaglom 1972, 1977). However, the weak dependence of the derived expressions on plume Reynolds number is unvalidated by geophysical-scale observations, and constant Stanton numbers appear to be at least as good a choice (McPhee 1992; McPhee et al. 1999; Jenkins et al. 2010). Equations (3) and (4) are slightly modified from their original form to ensure conservation of heat and salt (Jenkins et al. 2001). Values adopted for the physical constants are given in Table 1.

McPhee (1992) and McPhee et al. (1999) recommend the use of a simpler formulation for the heat balance at the ice-ocean interface,

$$
\begin{array}{r}
\dot{m} L_{i}+\dot{m} c_{i}\left(T_{f}-T_{i}\right)=c C_{d}^{1 / 2} U \Gamma_{T S}\left(T-T_{f}\right) \\
T_{f}=\lambda_{1} S+\lambda_{2}+\lambda_{3} Z_{b}
\end{array}
$$

where $T_{f}$ is the freezing temperature of the plume, which differs by an increment of $\lambda_{1}\left(S-S_{b}\right)$ from $T_{b}$. They show that, with an appropriate choice of Stanton number, $C_{d}^{1 / 2} \Gamma_{T S}$, this gives a good fit to observations of melting beneath sea ice under a broad range of conditions. Jenkins et al. (2010) show that observations of water properties and melting at one site on Ronne Ice Shelf can be fitted equally well by either (7)-(9) or (10) and (11). The latter, simpler formulation will be used in this paper along with the value for the Stanton number recommended by Jenkins et al. (2010). To make use of (10) and (11), we first rewrite (3) and (4) using (7) and (8),

$$
\begin{aligned}
\frac{d}{d X}(D U T) & =\dot{e} T_{a}+\dot{m}\left[T_{b}-\frac{L}{c}-\frac{c_{i}}{c}\left(T_{b}-T_{i}\right)\right] \text { and } \\
\frac{d}{d X}(D U S) & =\dot{e} S_{a}+\dot{m} S_{i},
\end{aligned}
$$

\begin{tabular}{|c|c|c|c|}
\hline Symbol & Value & Units & Description \\
\hline$E_{0}$ & $3.6 \times 10^{-2}$ & - & Entrainment coefficient \\
\hline$C_{d}$ & $2.5 \times 10^{-3}$ & - & Drag coefficient \\
\hline$C_{d}^{1 / 2} \Gamma_{T S}$ & $5.9 \times 10^{-4}$ & - & Stanton number \\
\hline$\lambda_{1}$ & $-5.73 \times 10^{-2}$ & ${ }^{\circ} \mathrm{C}$ & $\begin{array}{l}\text { Seawater freezing } \\
\text { point slope }\end{array}$ \\
\hline$\lambda_{2}$ & $8.32 \times 10^{-2}$ & ${ }^{\circ} \mathrm{C}$ & $\begin{array}{l}\text { Seawater freezing } \\
\text { point offset }\end{array}$ \\
\hline$\lambda_{3}$ & $7.61 \times 10^{-4}$ & ${ }^{\circ} \mathrm{C} \mathrm{m}^{-1}$ & $\begin{array}{l}\text { Depth dependence } \\
\text { of freezing point }\end{array}$ \\
\hline$L$ & $3.35 \times 10^{5}$ & $\mathrm{~J} \mathrm{~kg}^{-1}$ & $\begin{array}{l}\text { Latent heat of } \\
\text { fusion for ice }\end{array}$ \\
\hline$c$ & $2.009 \times 10^{3}$ & $\mathrm{~J} \mathrm{~kg}^{-1} \mathrm{~K}^{-1}$ & $\begin{array}{l}\text { Specific heat capacity } \\
\text { for ice }\end{array}$ \\
\hline$c_{i}$ & $3.974 \times 10^{3}$ & $\mathrm{~J} \mathrm{~kg}^{-1} \mathrm{~K}^{-1}$ & $\begin{array}{l}\text { Specific heat capacity } \\
\text { for seawater }\end{array}$ \\
\hline$\beta_{S}$ & $7.86 \times 10^{-4}$ & - & $\begin{array}{l}\text { Haline contraction } \\
\text { coefficient }\end{array}$ \\
\hline$\beta_{T}$ & $3.87 \times 10^{-5}$ & $\mathrm{~K}^{-1}$ & $\begin{array}{l}\text { Thermal expansion } \\
\text { coefficient }\end{array}$ \\
\hline$g$ & 9.81 & $\mathrm{~m} \mathrm{~s}^{-2}$ & $\begin{array}{l}\text { Acceleration due } \\
\text { to gravity }\end{array}$ \\
\hline$C_{d}^{1 / 2} \Gamma_{T}$ & $1.1 \times 10^{-3}$ & - & Thermal Stanton number \\
\hline$C_{d}^{1 / 2} \Gamma_{S}$ & $3.1 \times 10^{-5}$ & - & Haline Stanton number \\
\hline
\end{tabular}

TABLE 1. Physical constants.

and replace $T_{b}$ in (12) with $T_{f}$ for consistency with (10). The temperature and salinity at the interface no longer enter the problem, so a separate set of equations to diagnose interface properties is no longer needed.

Equations (1), (2), (5), (6), and (10)-(13) can be rearranged to give conservation equations for the fluxes of mass, momentum, buoyancy, and sensible heat within the plume,

$$
\begin{aligned}
\frac{d}{d X}(D U) & =\left(E_{0} \sin \alpha\right) U+\left(M_{0}\right) U \Delta T \\
\frac{d}{d X}\left(D U^{2}\right) & =(g \sin \alpha) D \Delta \rho-\left(C_{d}\right) U^{2} \\
\frac{d}{d X}(D U \Delta \rho) & =\left(\frac{d \Delta \rho_{a}}{d Z} \sin \alpha\right) D U+\left(M_{0} \Delta \rho_{i}^{\mathrm{ef}}\right) U \Delta T,
\end{aligned}
$$

$$
\begin{aligned}
\frac{d}{d X}(D U \Delta T)= & {\left[\left(T_{a}-T_{a f}\right) E_{0} \sin \alpha\right] U } \\
& +\left[\left(T_{i}^{\mathrm{ef}}-T_{i f}\right) M_{0}\right] U \Delta T-\left(\lambda_{3} \sin \alpha\right) D U
\end{aligned}
$$

where the density contrast $\Delta \rho$ and thermal driving $\Delta T$ of the plume are defined by

$$
\begin{aligned}
\Delta \rho & =\beta_{S}\left(S_{a}-S\right)-\beta_{T}\left(T_{a}-T\right) \text { and } \\
\Delta T & =T-T_{f},
\end{aligned}
$$


TABLE 2. Dimensional groupings of variables.

\begin{tabular}{|c|c|c|c|}
\hline Symbol & Expression & Units & Description \\
\hline$\Delta \rho_{a}$ & $\beta_{S}\left(S_{a}-S_{0}\right)-\beta_{T}\left(T_{a}-T_{0}\right)$ & - & $\begin{array}{l}\text { Ambient density } \\
\text { contrast }\end{array}$ \\
\hline$\Delta \rho_{i}$ & $\beta_{S}\left(S_{a}-S_{i}\right)-\beta_{T}\left(T_{a}-T_{i f}\right)$ & - & $\begin{array}{l}\text { Meltwater density } \\
\text { contrast }\end{array}$ \\
\hline$\Delta \rho_{i}^{\mathrm{ef}}$ & $\beta_{S}\left(S_{a}-S_{i}\right)-\beta_{T}\left(T_{a}-T_{i}^{\mathrm{ef}}\right)$ & - & $\begin{array}{c}\text { Effective meltwater } \\
\text { density contrast }\end{array}$ \\
\hline$T_{a f}$ & $\lambda_{1} S_{a}+\lambda_{2}+\lambda_{3} Z_{b}$ & ${ }^{\circ} \mathrm{C}$ & $\begin{array}{l}\text { Ambient freezing } \\
\text { point }\end{array}$ \\
\hline$T_{i f}$ & $\lambda_{1} S_{i}+\lambda_{2}+\lambda_{3} Z_{b}$ & ${ }^{\circ} \mathrm{C}$ & $\begin{array}{l}\text { Meltwater freezing } \\
\text { point }\end{array}$ \\
\hline$T_{i}^{\mathrm{ef}}$ & $T_{f}-\frac{L}{c}-\frac{c_{i}}{c}\left(T_{f}-T_{i}\right)$ & ${ }^{\circ} \mathrm{C}$ & $\begin{array}{l}\text { Effective meltwater } \\
\text { temperature }\end{array}$ \\
\hline$M_{0}$ & $\frac{C_{d}^{d} T_{S S}}{T_{f}-T_{i}^{\mathrm{ef}}}$ & $\left({ }^{\circ} \mathrm{C}\right)^{-1}$ & Melt rate factor \\
\hline
\end{tabular}

respectively, and other dimensional groupings are defined in Table 2. Note that, with the exception of the ambient properties (temperature, salinity, and vertical stratification) and the slope of the ice shelf base, which all represent the external forcing on the system, the terms in parentheses that appear as multipliers of the prognostic variables in (14)-(17) are nearly constant, with the only variables being $T_{f}, T_{i f}$, and $T_{i}^{\mathrm{ef}}$. To a good approximation, these can be made constant, because the effective ice temperature $T_{i}^{\mathrm{ef}}$ is on the order of $-100^{\circ} \mathrm{C}$, whereas the freezing point temperatures will vary by no more than a few tenths of a degree over the length scales of interest in this study. Therefore, $T_{f}$ can be replaced by $T_{a f}$ in the definition of the effective ice temperature and melt rate factor (Table 2), and freezing points can be evaluated at a fixed depth.

The next procedure is to nondimensionalize the variables in (14)-(17) using a set of physical scales appropriate for the region where the initial influx of freshwater is the dominant source of buoyancy for the plume. If the added meltwater were entirely negligible, the last terms on the right-hand sides of (14) and (16) would vanish and (14)-(16) would then be independent of (17) and have a solution analogous to that of a plume generated by a single source of buoyancy (Morton et al. 1956) but with the addition of frictional drag at the ice-ocean interface. It might also be anticipated that, over the relatively short length scales of interest in this study, the ambient stratification would not have a strong influence on the solution. If the first term on the right-hand side of (16) were also removed, (14)-(16) would have a very simple solution with constant buoyancy flux, constant velocity, and a linearly growing thickness. Using this solution to provide physical scales yields

$$
\frac{D^{\prime}}{L^{\prime}}=E_{0} \sin \alpha
$$

TABLE 3. Geometrical factors and length scales.

$$
\begin{aligned}
& \text { Symbol Expression Units Description } \\
& \mathrm{A}_{0}^{U}\left(\frac{\sin \alpha}{E_{0} \sin \alpha+C_{d}}\right)^{1 / 3} \quad-\begin{array}{c}
\text { Geometrical factor } \\
\text { for velocity }
\end{array} \\
& \mathrm{A}_{0}^{T} \quad\left[1-\frac{M_{0}\left(T_{i}^{\mathrm{ef}}-T_{i f}\right)}{E_{0} \sin \alpha}\right]^{-1} \\
& L^{\prime} \frac{\left(D_{X 0} U_{X 0} \Delta \rho_{i}\right)^{2 / 3}}{M_{0} \Delta \rho_{i}^{\mathrm{ef}} g^{1 / 3} \mathrm{~A}_{0}^{U} \mathrm{~A}_{0}^{T}\left(T_{a}-T_{a f}\right)_{X 0}} \quad \mathrm{~m} \begin{array}{c}
\text { Governing length } \\
\text { scale }
\end{array} \\
& L_{\rho a} \frac{M_{0} \Delta \rho_{i}^{\mathrm{ef}} \mathrm{A}_{0}^{T}\left(T_{a}-T_{a f}\right)_{X 0}}{\left(-d \Delta \rho_{a} / d X\right) E_{0} \sin ^{2} \alpha} \\
& L_{T f} \frac{\mathrm{A}_{0}^{T}\left(T_{a}-T_{a f}\right)_{X 0}}{\lambda_{3} \sin \alpha} \\
& L_{\text {rot }}^{\text {hor }} \frac{0.24 C_{d}^{1 / 2}}{f E_{0} \sin \alpha \cos \alpha} \mathrm{A}_{0}^{U}\left(g D_{X 0} U_{X 0} \Delta \rho_{i}\right)^{1 / 3} \text { m Rotational length } \\
& \begin{array}{cc}
L_{\text {rot }}^{\mathrm{ver}} \frac{2.2}{f E_{0} \sin ^{2} \alpha}\left(g D_{X 0} U_{X 0} \Delta \rho_{i}\right)^{1 / 3} \quad \mathrm{~m} \begin{array}{c}
\text { Rotational length } \\
\text { scale (vertical) }
\end{array} \\
\hline
\end{array} \\
& \begin{aligned}
U^{\prime} & =\mathrm{A}_{0}^{U}\left(g D^{\prime} U^{\prime} \Delta \rho^{\prime}\right)^{1 / 3}, \text { and } \\
\Delta \rho^{\prime} & =\frac{D_{X 0} U_{X 0}}{D^{\prime} U^{\prime}} \Delta \rho_{i},
\end{aligned}
\end{aligned}
$$

where $D_{X 0}$ and $U_{X 0}$ are the initial thickness and velocity of the plume, the effect of interface slope on the plume velocity is encapsulated in a geometrical factor $A_{0}^{U}$ (Table 3), and the initial density contrast $\Delta \rho_{i}$ is that of meltwater at the freezing point (Table 2). The geometrical factor reflects the changing balance between slope-dependent, gravitational forcing and drag generated both by the solid ice-ocean boundary and by the slope-dependent entrainment of stationary ambient fluid. In the case of (17), the consideration of relatively short length scales motivates dropping the final term involving the change of the freezing point temperature with depth. The temperature of the plume relative to the freezing point then evolves toward an equilibrium value given by

$$
\begin{aligned}
E_{0} \sin \alpha U \Delta T= & E_{0} \sin \alpha U\left(T_{a}-T_{a f}\right) \\
& +M_{0}\left(T_{i}^{\mathrm{ef}}-T_{i f}\right) U \Delta T,
\end{aligned}
$$

and this provides a fourth physical scale,

$$
\Delta T^{\prime}=\mathrm{A}_{0}^{T}\left(T_{a}-T_{a f}\right)_{X 0},
$$

where the subscript $X 0$ again indicates initial conditions and the geometrical term $A_{0}^{T}$ (Table 3 ) reflects the changing balance between entrainment, which forces the plume temperature toward that of the ambient and scales with the slope, and melting, which forces the plume temperature toward the freezing point and is independent of 
slope. Now it only remains to choose a length scale. This is taken as the distance over which the input of buoyancy from melting is equal to the initial buoyancy flux. For a uniform ambient environment, (16) gives

$$
L^{\prime}=\frac{D_{X 0} U_{X 0} \Delta \rho_{i}}{M_{0} \Delta \rho_{i}^{\text {ef }} U^{\prime} \Delta T^{\prime}} .
$$

These physical scales can now be used to define a set of dimensionless variables,

$$
x=\frac{X}{L^{\prime}}, \quad d=\frac{D}{D^{\prime}}, \quad u=\frac{U}{U^{\prime}}, \quad \delta \rho=\frac{\Delta \rho}{\Delta \rho^{\prime}},
$$

and $\quad \delta T=\frac{T-T_{f}}{\Delta T^{\prime}}$

which on substitution into (14)-(17) yield

$$
\begin{aligned}
\frac{d}{d x}(u d) & =u+\left(\frac{1}{\delta \rho_{i}^{\mathrm{ef}}}\right) u \delta T, \\
\frac{d}{d x}\left(u^{2} d\right) & =\left(1+\frac{C_{d}}{E_{0} \sin \alpha}\right) \delta \rho d-\left(\frac{C_{d}}{E_{0} \sin \alpha}\right) u^{2}, \\
\frac{d}{d x}(\delta \rho u d) & =-\left(\frac{1}{l_{\rho a}}\right) u d+u \delta T, \text { and } \\
\frac{d}{d x}(\delta T u d) & =\left(\delta T_{a}\right) u+\left(\frac{\delta T_{i}^{\mathrm{ef}}}{\delta \rho_{i}^{\mathrm{ef}}}\right) u \delta T-\left(\frac{1}{l_{T f}}\right) u d,
\end{aligned}
$$

where

$$
\begin{aligned}
& l_{\rho a}=\frac{-\Delta \rho^{\prime}}{\left(d \Delta \rho_{a} / d Z\right) \sin \alpha L^{\prime}} \text { and } \\
& l_{T f}=\frac{\Delta T^{\prime}}{\lambda_{3} \sin \alpha L^{\prime}}
\end{aligned}
$$

are the scaled lengths over which the ambient density changes by $\Delta \rho^{\prime}$ and over which the freezing point temperature changes by $\Delta T^{\prime}$, respectively.

Initial conditions for (27)-(30) are based on a flow of freshwater, which is assumed to have a temperature equal to the pressure freezing point, emerging from beneath a glacier or ice stream. This gives

$$
\begin{aligned}
d_{x 0} & =\frac{M_{0} \Delta \rho_{i}^{\mathrm{ef}} A_{0}^{T}\left(T_{a}-T_{a f}\right)_{X 0}}{\Delta \rho_{i} E_{0} \sin \alpha}, \quad u_{x 0}=1, \\
\delta \rho_{x 0} & =\frac{1}{d_{x 0}}, \quad \delta T_{x 0}=0,
\end{aligned}
$$

where the dimensionless plume thickness is chosen to be consistent with a dimensionless velocity of 1 using a combination of Eqs. (20), (24), and (25). Solutions to Eqs. (27)-(30) depend on the initial flow of freshwater, the temperature of the ambient ocean relative to its freezing point, the vertical stratification of the ambient water column, and the slope of the ice-ocean interface. Note that the absolute temperature of the ambient only appears in the density terms, where it plays a relatively minor role. The absolute depth of the ice-ocean interface is therefore arbitrary; only the rate at which the depth changes matters for the solution of the equations. Values used in this study for the physical constants that appear in the scaling (Table 1) follow the usage of Jenkins (1991) and Jenkins et al. (2010).

The equations presented above will be considered a valid approximation only while the terms that have been retained in the momentum equation are larger than the neglected Coriolis acceleration. For near-horizontal plumes beneath ice shelves, the scale at which rotation begins to dominate the dynamics can be estimated as the larger of the Rossby radius of deformation or the distance at which the plume thickness exceeds the Ekman length. In practice, it is the latter length scale that exerts the primary control over the plume behavior, so that the limiting plume thickness is

$$
D_{\text {rot }}^{\text {hor }}=\left(\frac{2 \nu}{f \cos \alpha}\right)^{1 / 2} .
$$

The viscosity can be estimated as

$$
\nu=C_{d}^{1 / 2} U^{\prime} \Lambda_{\text {rot }}
$$

where $\Lambda_{\text {rot }}$ is the rotationally limited mixing length in the ice-ocean boundary layer, given by McPhee (1994) as

$$
\Lambda_{\mathrm{rot}}=\frac{0.028 C_{d}^{1 / 2} U^{\prime}}{f \cos \alpha}
$$

Combining (34)-(36) gives

$$
D_{\text {rot }}^{\text {hor }}=\frac{0.24 C_{d}^{1 / 2} \mathrm{~A}_{0}^{U}}{f \cos \alpha}\left(g D_{X 0} U_{X 0} \Delta \rho_{i}\right)^{1 / 3}
$$

for near-horizontal plumes. For near-vertical plumes, rotation plays a negligible role in the along-stream momentum balance but limits the lateral spread of the plume away from the ice-ocean interface. Based on laboratory measurements, Fernando and Ching (1993) give the limiting plume thickness as

$$
D_{\text {rot }}^{\mathrm{ver}}=\frac{2.2}{f \sin \alpha}\left(g D_{X 0} U_{X 0} \Delta \rho_{i}\right)^{1 / 3}
$$

for near-vertical plumes. 

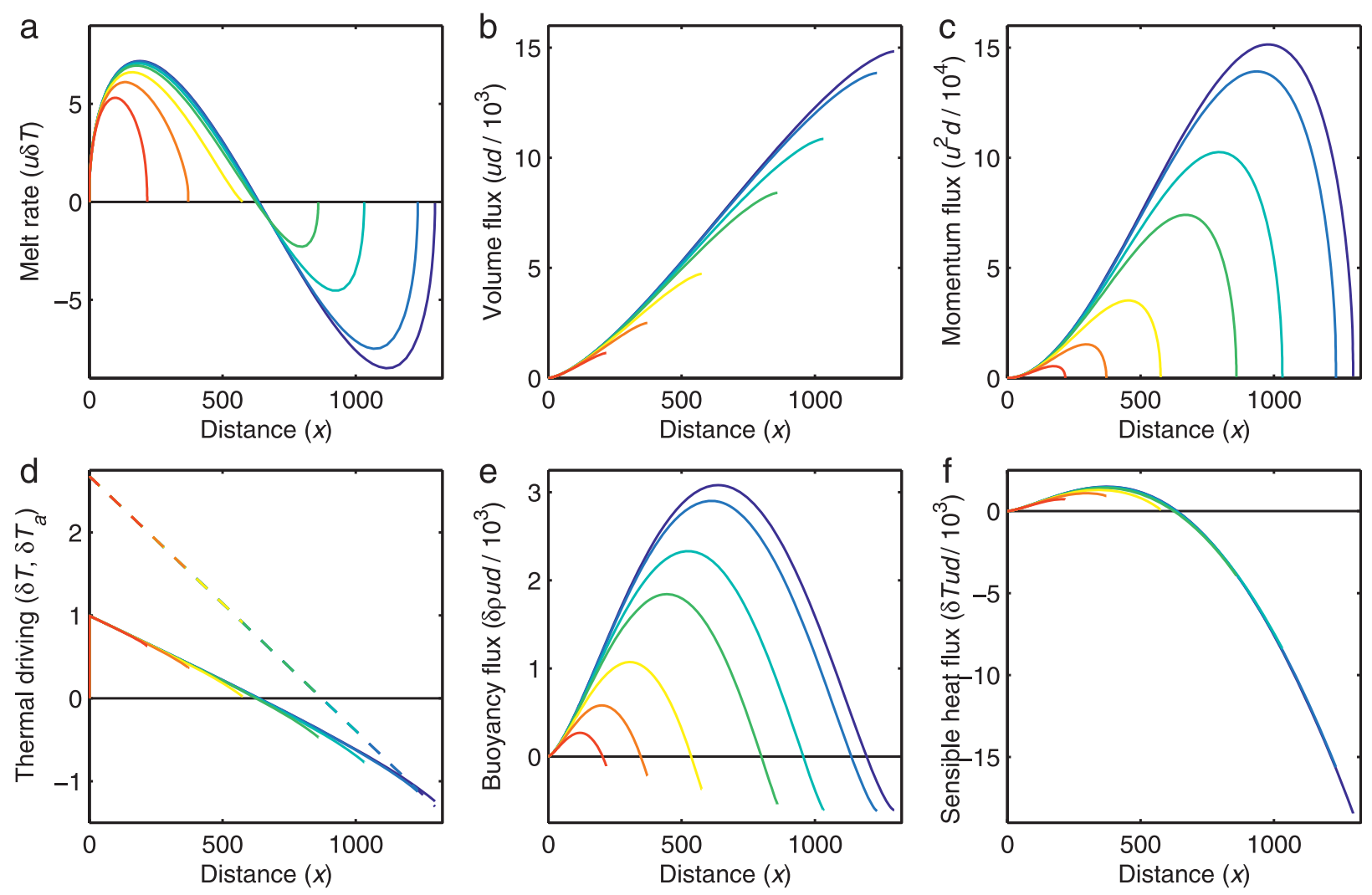

Ambient stratification $\left(\mathrm{m}^{-1}\right)$ :

0

$$
-1 \mathrm{e}-8
$$$$
-5 e-8
$$$$
-1 e-7
$$

FIG. 2. Dimensionless (a) melt rate, (b) volume flux, (c) momentum flux, (d) thermal driving, (e) buoyancy flux, and (f) sensible heat flux plotted as a function of dimensionless distance for a plume initiated by a freshwater flux of $5 \times 10^{-5} \mathrm{~m}^{2} \mathrm{~s}^{-1}$ beneath an ice shelf with a basal slope $(\sin \alpha)$ of 0.01 . The ambient ocean has a temperature $2^{\circ} \mathrm{C}$ above the freezing point at the starting depth, a salinity of 35 , and varying stratification indicated by lines of differing color. The resulting ambient thermal driving is indicated by the dashed lines in (d).

\section{Results}

The main goal of this paper is to understand the behavior of the model for $x \sim 1$, but it is instructive to first examine the far-field behavior for $x \gg 1$. Figure 2 shows dimensionless results plotted as a function of dimensionless distance $x$ for a set of parameters typical of the region near the grounding line of one of the larger Antarctic ice shelves and a range of values for the ambient stratification. With unstratified ambient water, the behavior of the plume is ultimately controlled by the depth dependence of the freezing point, which is responsible for the linear fall in the ambient thermal driving with distance seen in Fig. 2d. As the plume rises, heat from entrainment is required to maintain its temperature above the rising freezing point, with more as the volume flux of the plume rises (Fig. 2b). However, with a constant temperature environment, the sensible heat available from entrainment, which is determined by the ambient thermal driving (Fig. 2d), falls on account of the decreasing depth. The result is a near-linear fall in the plume thermal driving (Fig. 2d) and a transition from melting to freezing where it passes through zero (Figs. 2a,d). Although the addition of meltwater increases the buoyancy flux, subsequent freezing decreases it (Figs. 2a,e), and it reaches zero when all the added meltwater has been refrozen.

This is the classic "ice pump" behavior described by many authors. In Fig. 2, the integration has been continued beyond the point where the buoyancy flux changes sign (Fig. 2e) and inertia becomes the only source of forward momentum. The end point of the integrations is where the momentum flux reaches zero (Fig. 2c), so in the case of a uniform ambient water column, where melting and freezing are the only sources and sinks of plume buoyancy, total freezing exceeds total melting. With the introduction of ambient stratification, the ambient density falls with the rise of the plume, giving 

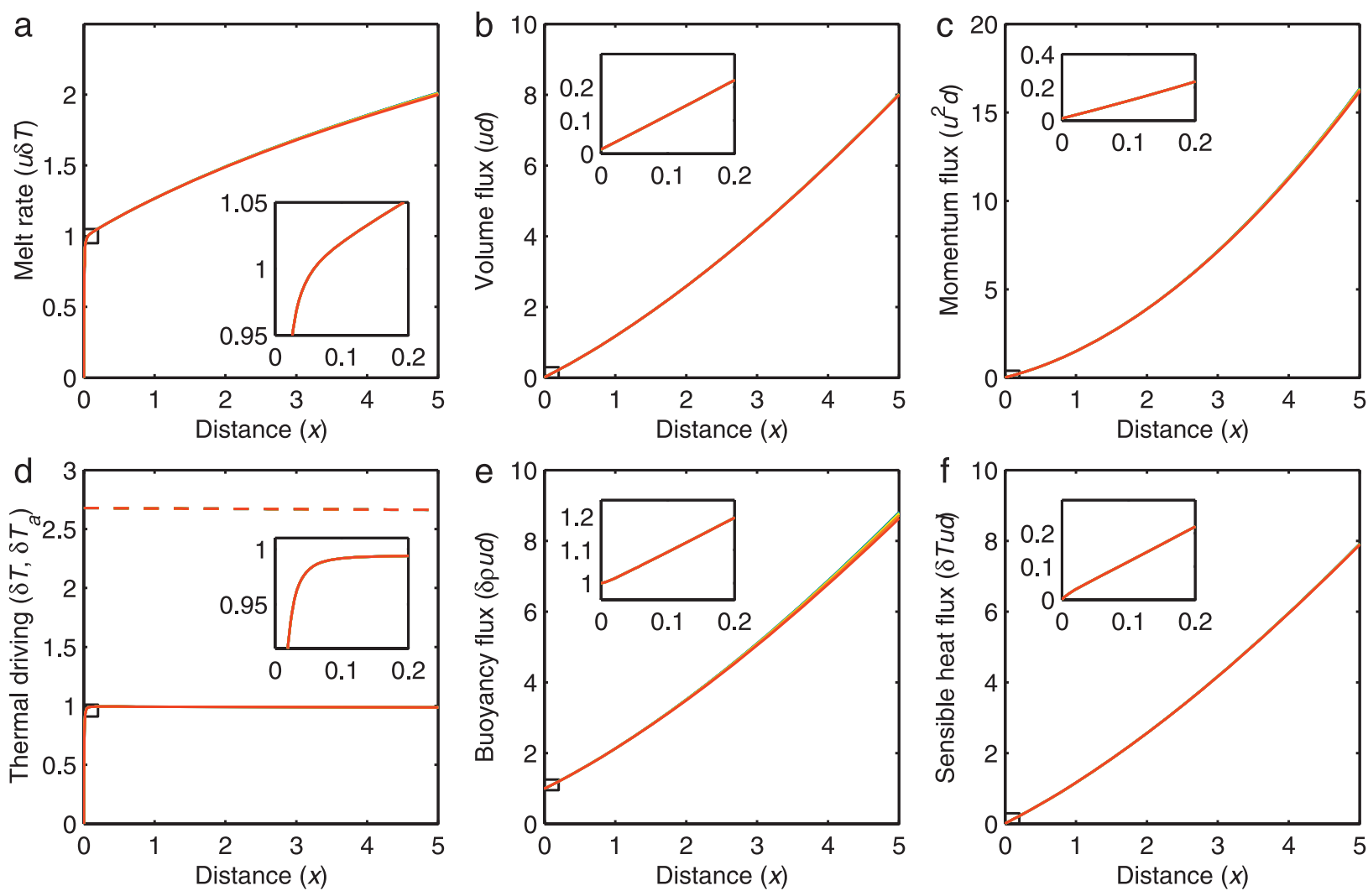

Ambient stratification $\left(\mathrm{m}^{-1}\right)$ :

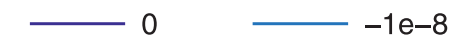

$-5 e-8$

$-1 e-7$

$-2.5 e-7--5 e-7$

$-1 e-6$

FIG. 3. As in Fig. 2, but focused on the region where the dimensionless distance from the grounding line is 5 or less, with the region where the dimensionless distance is 0.2 or less (within the boxes) expanded in the insets.

an additional buoyancy sink and bringing the point where the buoyancy flux changes sign closer to the origin (Fig. 2e). Melting now exceeds freezing (Fig. 2a) because the plume loses momentum in the freezing zone (Figs. 2a,c). If the stratification is sufficiently strong, the fall in ambient density exceeds the buoyancy input by melting and the buoyancy flux changes sign in the melting zone (Figs. 2a,e), thus eliminating freezing altogether.

In the examples illustrated in Fig. 2, despite the range in far-field response, the solution for $x \sim 1$ (Fig. 3) is almost identical in every case. As the freshwater inflow mixes with the ambient water, there is a period of rapid adjustment $(x<0.05)$ until the thermal driving reaches a steady value (Fig. 3d). At this point, the scaled melt rate $u \delta T$ is 1 , and it increases, with only a slight nonlinearity, toward a value of approximately 2 at $x=5$ (Fig. 3a), as the volume, momentum, buoyancy, and sensible heat fluxes steadily rise (Figs. 3b-f). At $x=5$, the initial buoyancy flux represents only about $12 \%$ of the total (Fig. 3e), but the solutions remain sufficiently self-similar for the melt rate to be reasonably approximated by the same straight line (Fig. 3a). It is therefore possible to make the rather general statement that, over the region where $x<5$, the average melt rate is about 1.5 .

For the particular choice of parameters used for Figs. 2 and 3, both the length scales defined in Eqs. (31) and (32) are $\sim 100$ or greater, so they only play a role in the far-field solutions; however, with increasing stratification or decreasing ambient temperature, the far-field behavior described above eventually affects the region where $x \sim 1$. Figure 4 shows solutions for the same parameter choice as above, but with the ambient stratification chosen to give $l_{\rho a}$ ranging from 50 to 0.1 . For the strongest stratification, the loss of buoyancy is sufficient to reduce the momentum flux and melt rate to zero at $x<1$ (Figs. 4a,c). In general, buoyancy and melting both peak near $x=l_{\rho a}$ and fall back to one near $x=2 l_{\rho a}$ (Figs. 4a,e). For the case where $l_{\rho a}=5$, the mean melt rate for $x<5$ is 1.4. Figure 5 shows solutions for a uniform ambient environment with the temperature 

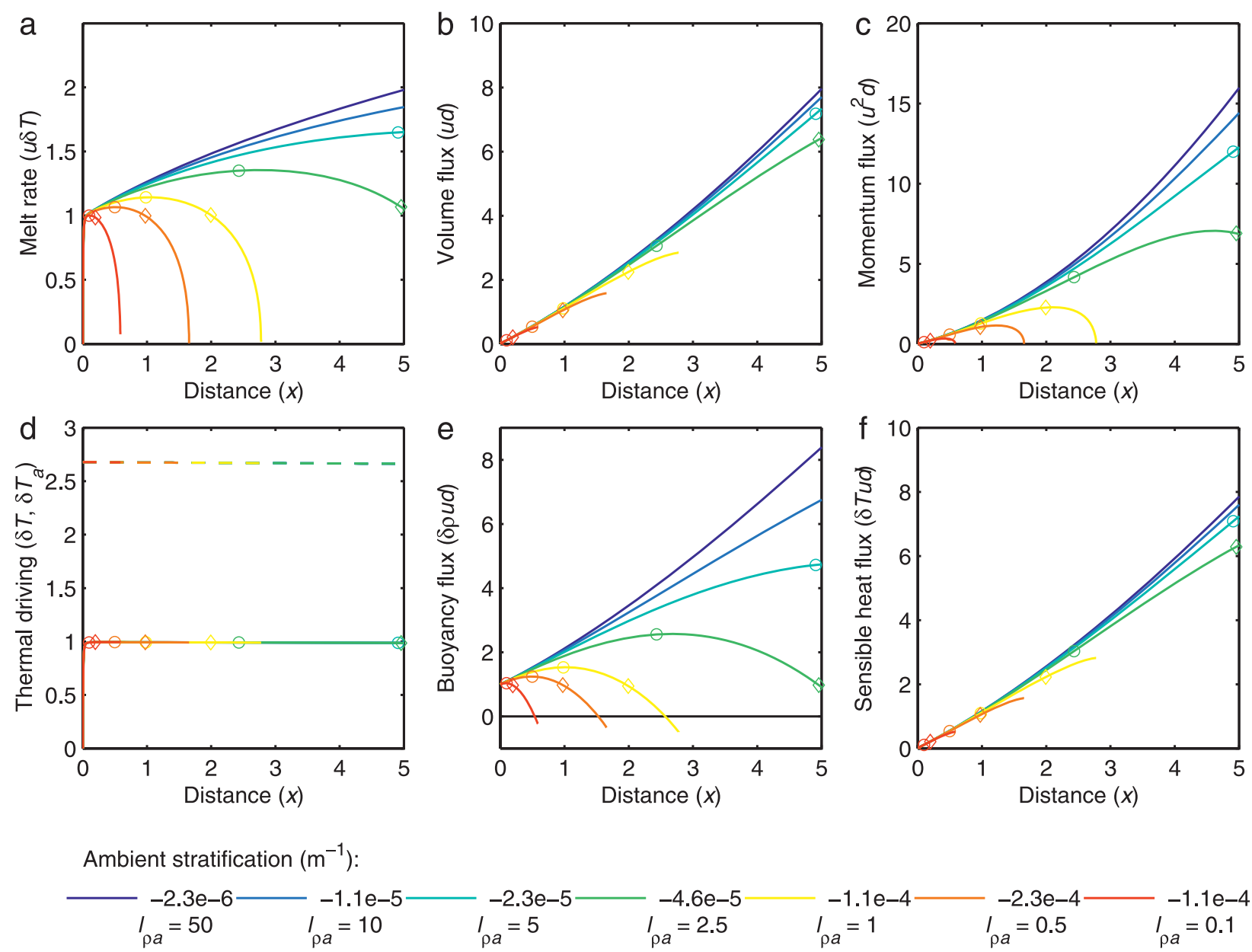

FIG. 4. As in Figs. 2 and 3, but with stronger ambient stratification, indicated by lines of differing color, chosen such that values for $l_{\rho a}$ range from 50 down to 0.1 . Colored circles and diamonds indicate where $x=l_{\rho a}$ and $x=2 l_{\rho a}$, respectively.

chosen such that $l_{T f}$ ranges from 75 to 0.5 . In general, the sensible heat flux peaks at $x=l_{T f}$ and falls back to zero at $x=2 l_{T f}$ (Fig. 5f). The transition from melting to freezing and the associated peak in the buoyancy flux therefore both occur near $x=2 l_{T f}$ (Figs. 5a,e), and for the smallest values of $l_{T f}$ this transition occurs at $x \sim 1$. For $l_{T f}=20$, the melt rate peaks near $x=10$ and the mean over $x<5$ is 1.4. Finally, Fig. 6 illustrates the melt rates simulated for a wide range of parameters. In all cases, the solutions over the region up to $x=5, x=l_{\rho a}$, or $x=l_{T f} / 4$-whichever is the smallest—give melt rates that deviate by no more than about $20 \%$ from the approximate linear relationship $\dot{m}=1+0.2 x$. Hence, if the zone of applicability of the model is defined by the above limits, mean melt rates between 0 and $x$ follow the approximate relationship $\bar{m}=1+0.1 x$ to within about $10 \%$.

Using this general result, it is possible to write an analytical expression that approximates the melt rate over the zone near the grounding line of an ice shelf or tidewater glacier. In dimensional units, the melt rate can be expressed as

$$
\dot{m}=\left(1+0.2 \frac{X}{L^{\prime}}\right) M_{0} U^{\prime} \Delta T^{\prime}
$$

which leads to the expression

$$
\dot{m}=\left(1+0.2 \frac{X}{L^{\prime}}\right) A_{0}^{U} A_{0}^{T} M_{0}\left(g D_{X 0} U_{X 0} \Delta \rho_{i}\right)^{1 / 3}\left(T_{a}-T_{a f}\right)_{X 0}
$$

valid for

$$
\begin{aligned}
& \left(X<5 L^{\prime}\right) \cap\left(X<L_{\rho a}\right) \cap\left(X<L_{T f} / 4\right) \cap\left(X<L_{\text {rot }}^{\text {hor }}\right) \\
& \cap\left(X<L_{\text {rot }}^{\text {ver }}\right) .
\end{aligned}
$$

The physical length scales are summarized in Table 3 and are illustrated in Fig. 7 for ice-ocean interface slopes 

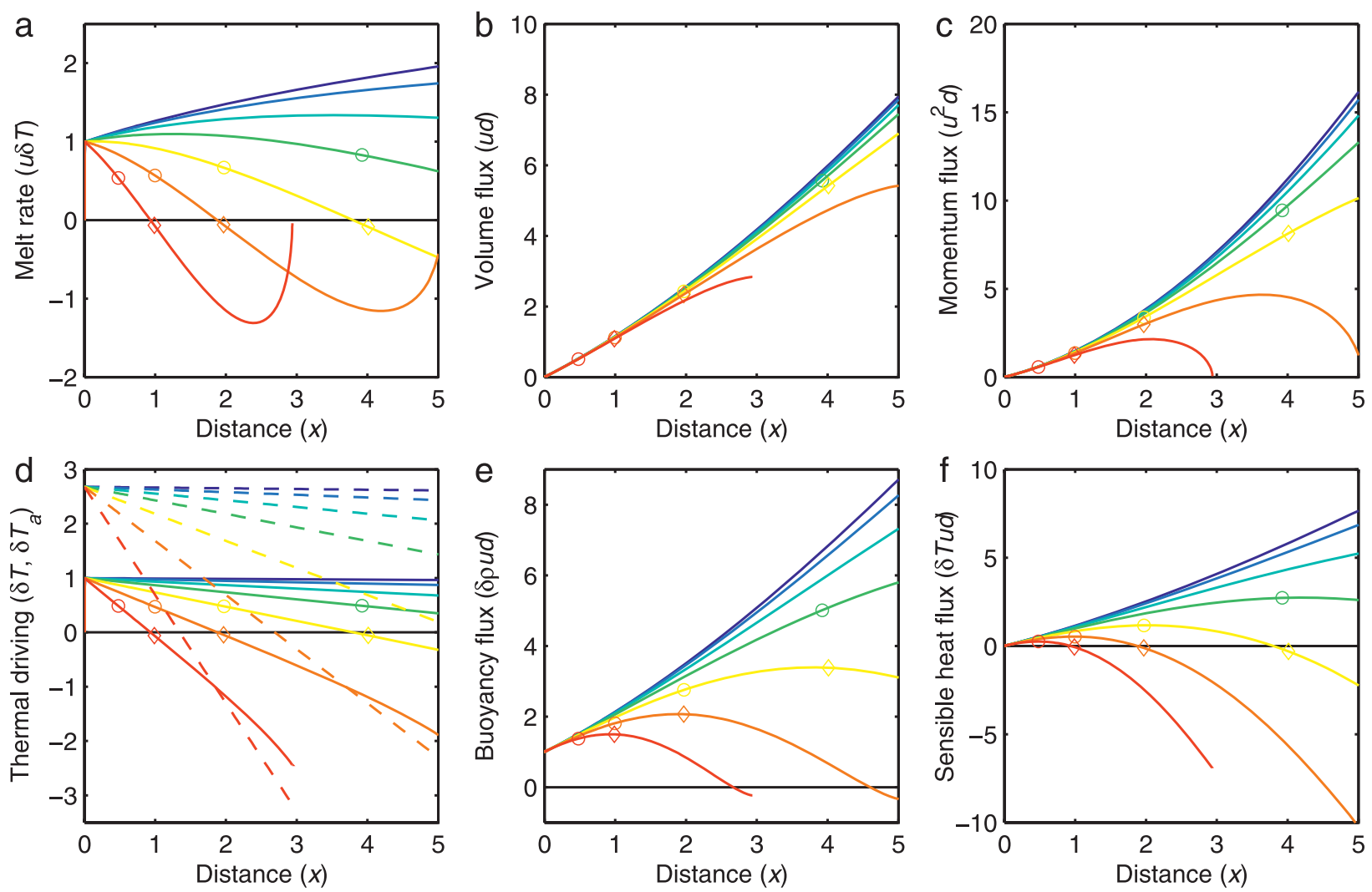

Ambient temperature relative to freezing point $\left({ }^{\circ} \mathrm{C}\right)$ :

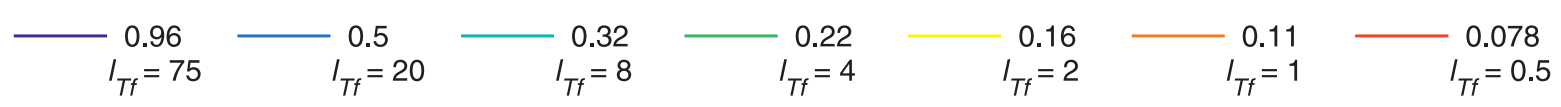

FIG. 5. As in Figs. 2 and 3, but with zero ambient stratification and ambient temperatures, indicated by lines of differing color, chosen such that values for $l_{T f}$ range from 75 down to 0.5 . Colored circles and diamonds indicate where $x=l_{T f}$ and $x=2 l_{T f}$, respectively.

typical of the grounding zone of an ice shelf $(0.01)$ and the calving front of a tidewater glacier (1). The governing length scale of the problem $L^{\prime}$ is proportional to the reciprocal of the ambient water temperature and to the initial freshwater flux to the power of two-thirds. The rotational length scales are also increasing functions of the initial flux but to the lower power of one-third and are independent of the ambient temperature. Therefore, $L_{\mathrm{rot}}<5 L^{\prime}$ at the lowest ambient temperatures, whereas the crossover point, above which $L_{\text {rot }}>5 L^{\prime}$, occurs at a progressively higher temperature as the initial flux increases. However, for both near-horizontal and near-vertical plumes, $L_{T f}$ sets a tighter constraint on the validity of Eq. (40) at low ambient temperatures, so that rotation never sets the limiting length scale in practice. For near-horizontal plumes, only the strongest stratification can provide a stricter limit, so the zone of validity of Eq. (40) is generally determined by $L_{T f}$ and $5 L^{\prime}$ and ranges from hundreds of meters to many tens of kilometers. For near-vertical plumes, the more rapid entrainment means that stratification comes into play much more readily, with the strongest stratification limiting the zone of validity of Eq. (40) to meter scales. For weakly stratified ambient waters, the same combination of $5 \mathrm{~L}^{\prime}$ at high ambient temperature and $L_{T f}$ at low ambient temperature sets the limiting length scale at tens of meters to kilometers.

Within the zone of model validity, the melt rate scales linearly with the ambient temperature and as the cube root of the initial freshwater flux. The actual melt rates given by (40) at $x=0$ for a vertical ice face and the same range of initial freshwater fluxes and ambient properties as used in Fig. 7 are shown in Fig. 8a. The combination of high ambient temperature and high initial freshwater flux can lead to melt rates of many meters per day. At $x=5$, the melt rate will be twice the plotted values and the average over the range $x<5$ will be $50 \%$ above the plotted values. The effect of ice-ocean interface slope is encapsulated in the two geometrical factors (Table 3), plotted along with their product in Fig. $8 \mathrm{~b}$ in the form 

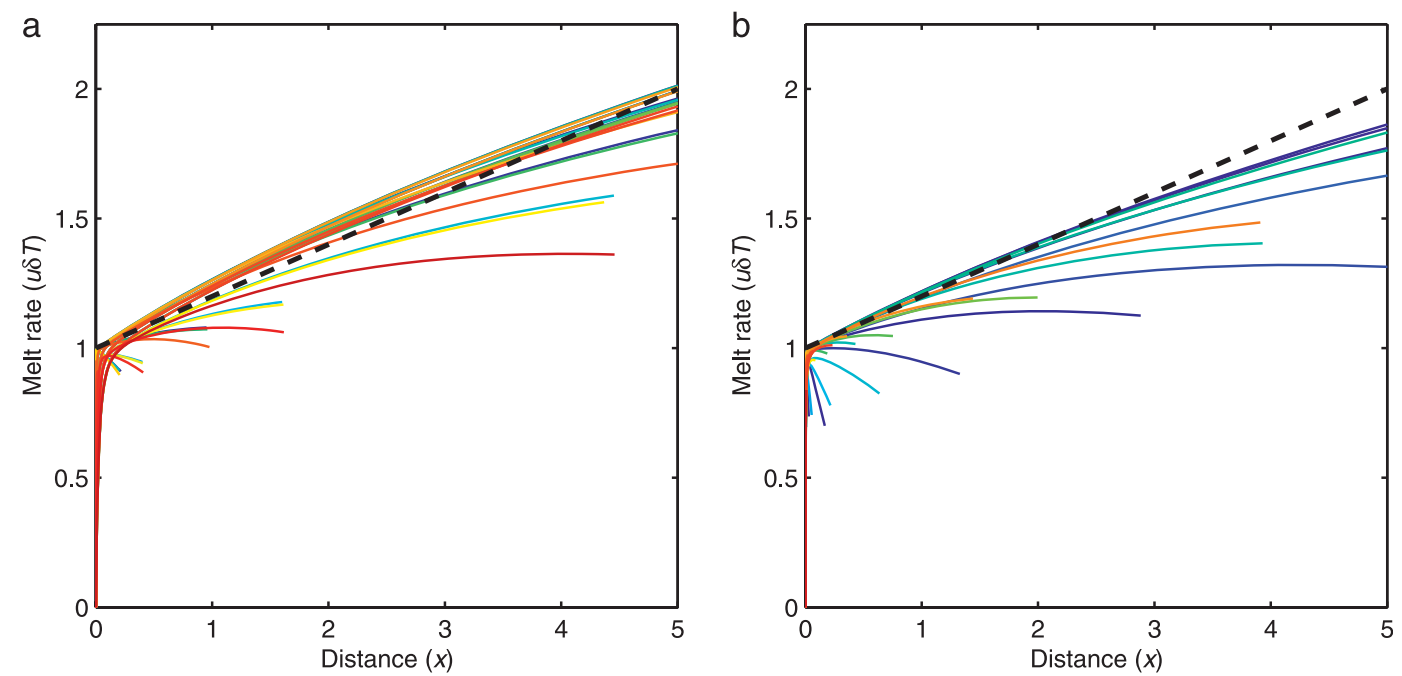

FIG. 6. Dimensionless melt rates obtained for plumes with ambient stratification ranging from 0 to $-1 \times 10^{-6} \mathrm{~m}^{-1}$, ambient temperature ranging from $0.1^{\circ}$ to $10^{\circ} \mathrm{C}$ above the freezing point, initial freshwater flux ranging from $5 \times 10^{-5}$ to $5 \times 10^{-1} \mathrm{~m}^{2} \mathrm{~s}^{-1}$, and ice shelf basal slopes ( $\sin \alpha$ ) of (a) 0.01 and (b) 1 . In all cases, the ambient salinity is 35 and the solutions have been terminated at the point where $x=l_{\rho a}$ or $x=l_{T f} / 4$ if either condition occurs before $x=5$.

of scaling factors to be applied to the plotted melt rates in order to obtain the melt rate for any given interface slope. For a basal slope of 0.01 , considered above, the scaling factor is about 0.2 , so the peak melt rate for an ambient temperature $10^{\circ} \mathrm{C}$ above the freezing point and an initial freshwater flux of $5 \times 10^{-1}$ $\mathrm{m}^{2} \mathrm{~s}^{-1}$ is around $650 \mathrm{~m} \mathrm{yr}^{-1}$. For a slope of 0.1 , the scale factor is 0.75 , whereas, for a slope of 0.001 , it falls to 0.014 .

\section{Specific examples}

The results of applying the model to a number of more or less realistic examples are presented in Table 4 and

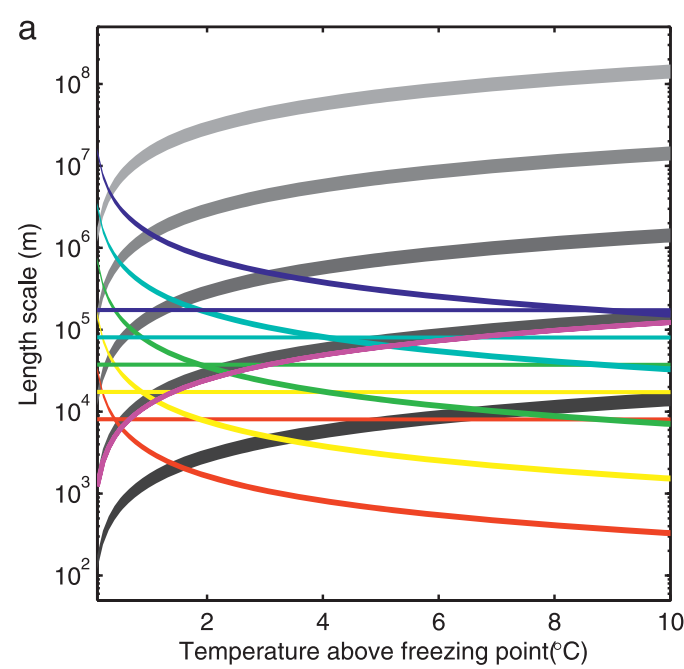

Initial freshwater flux $\left(\mathrm{m}^{2} \mathrm{~s}^{-1}\right)$ :

$-5 \mathrm{e}-5-5 \mathrm{e}-4-5 \mathrm{e}-3-5 \mathrm{e}-2-5 \mathrm{e}-1$ b

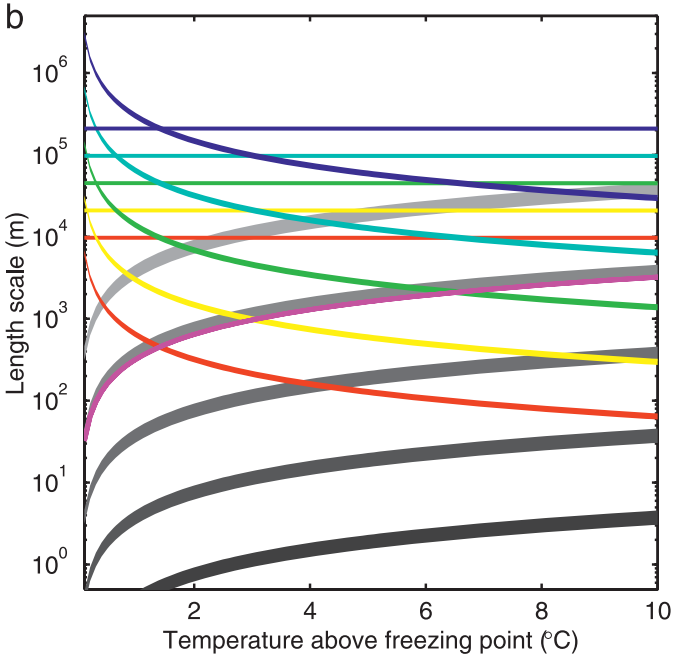

Ambient stratification $\left(\mathrm{m}^{-1}\right)$ :

$-1 \mathrm{e}-9-1 \mathrm{e}-8-1 \mathrm{e}-7--1 \mathrm{e}-6-1 \mathrm{e}-5$

FIG. 7. Governing length scales for plumes flowing along an ice-ocean interface having a slope $(\sin \alpha)$ of (a) 0.01 and (b) 1 plotted as functions of ambient temperature. Multicolored lines indicate $5 L^{\prime}$ (curves) and $\mathrm{L}_{\text {rot }}$ (straight lines) calculated for a range of initial freshwater fluxes and a latitude of $75^{\circ}$, gray lines indicate $L_{\rho a}$ for a range of ambient stratifications, and the magenta line indicates $L_{T f}$. Line widths indicate the spread of values obtained for ambient salinities ranging from 25 to 35 . 

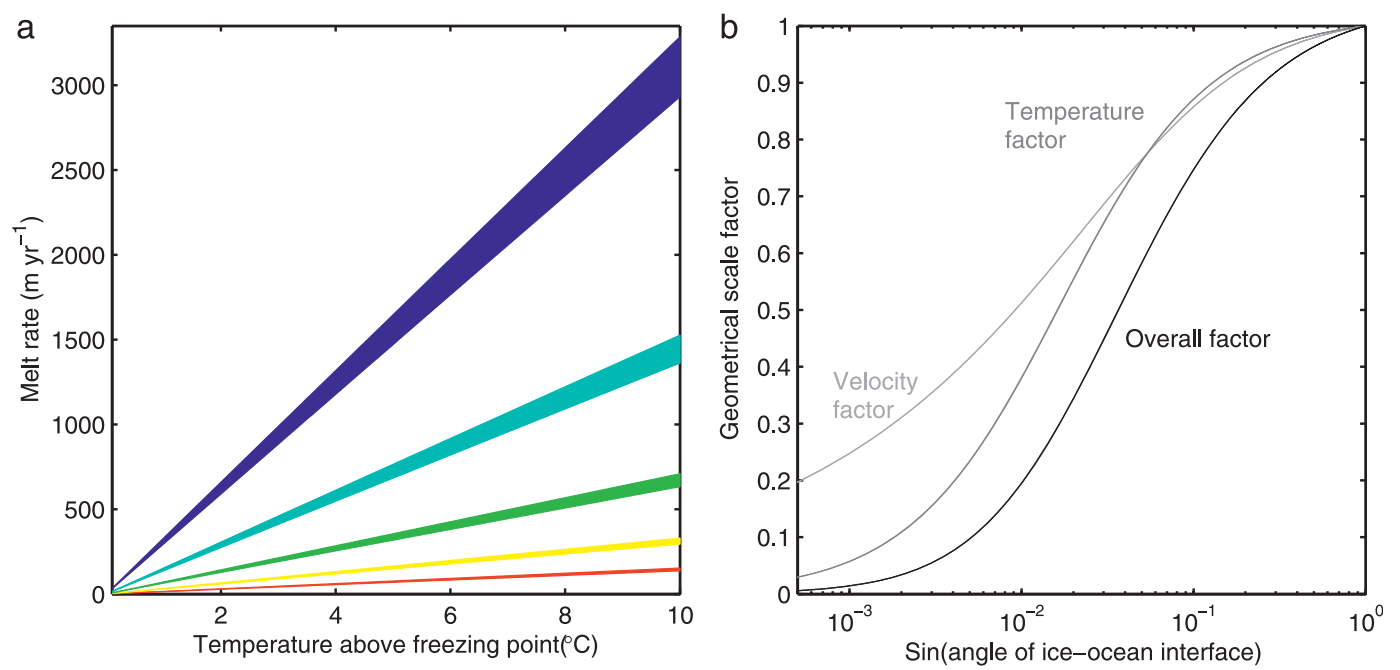

Initial freshwater flux $\left(\mathrm{m}^{2} \mathrm{~s}^{-1}\right)$ :

$-5 \mathrm{e}-5-5 \mathrm{e}-4-5 \mathrm{e}-3-5 \mathrm{e}-2-5 \mathrm{e}-1$

FIG. 8. (a) Melt rates at $X=0$ derived from Eq. (40) for an ice-ocean interface slope ( $\sin \alpha$ ) of 1 and (b) multiplication factor required to scale the melt rates for interface slopes down to $5 \times 10^{-4}$. The overall factor is the product of temperature-related $\left(A_{0}^{T}\right)$ and velocity-related $\left(A_{0}^{U}\right)$ scale factors (Table 3). Line widths indicate the spread of values obtained for ambient salinities ranging from 25 to 35 .

discussed below. They cover the full range of likely subglacial regimes from Antarctic ice streams, where the only sources of basal meltwater are geothermal and frictional heating, to temperate tidewater glaciers, where considerable quantities of surface meltwater drain to the glacier bed. Given that data on the water column structure near the grounding lines of ice shelves and tidewater glaciers are almost completely lacking, temperatures are assumed uniform and defined by far-field observations, whereas the ambient density gradient is that used by Jenkins (1991). To simplify comparisons between the differing glacier configurations, this same value for the stratification is used throughout. The strength of the stratification has little impact on the computed melt rates because it does not enter (40) directly, only affecting the average melt rate when it is the controlling factor in setting the region over which (40) is valid. Stratification does play a major role in the ultimate evolution of the plume (Fig. 2), determining the level at which it attains neutral buoyancy and hence whether a zone of freezing exists, but the details of this far-field behavior are beyond the scope of the current discussion.

\section{a. Rutford Ice Stream}

In the original application of the model presented in this paper, Jenkins (1991) studied melting and freezing along a flow line on the Filchner-Ronne Ice Shelf. Initial conditions for the integration were derived from the estimated flux of freshwater emerging at the grounding line of Rutford Ice Stream. The flux estimate was based on an assumed mean melt rate of $0.01 \mathrm{~m} \mathrm{yr}^{-1}$ over a 150-km length of the ice stream. Jenkins (1991) concluded that the results were insensitive to this poorly known initial condition. However, this statement was based on a comparison of the simulated melt rate over the entire $800 \mathrm{~km}$ of the flow line when the model was started with a freshwater flux that was varied by a factor of 10 . For this range of initial freshwater fluxes, the melt rate at the grounding line changes by a factor of nearly 5 (Table 4). As the initial flux grows, the factor that limits the applicability of (40) evolves from the small size of the initial buoyancy flux $\left(5 L^{\prime}\right)$ to the change in the pressure freezing point with depth $\left(L_{T f}\right)$. Melt rates derived from (40) are compared over the smallest of these length scales, which is defined as $L_{\text {limit }}$ in Table 4 , and the average over this region, where (40) is valid in all cases, varies by a factor closer to 3 . The mean melt rates over the same region derived from the full model [(1)-(9); results in the last column of Table 4] agree to within $10 \%$ of those obtained with the reduced model [(40)]. These results demonstrate that melting over the first few kilometers of floating ice on Rutford Ice Stream is indeed sensitive to the flow of freshwater across the grounding line.

\section{b. Whillans Ice Stream}

For Whillans Ice Stream, most of the parameters are assumed to take the same values as in the previous example. Despite the shallower grounding line, the steeper ice shelf base means that the background flow of freshwater produces a similar melt rate to that calculated for 
TABLE 4. Model results for selected ice shelves and tidewater glaciers.

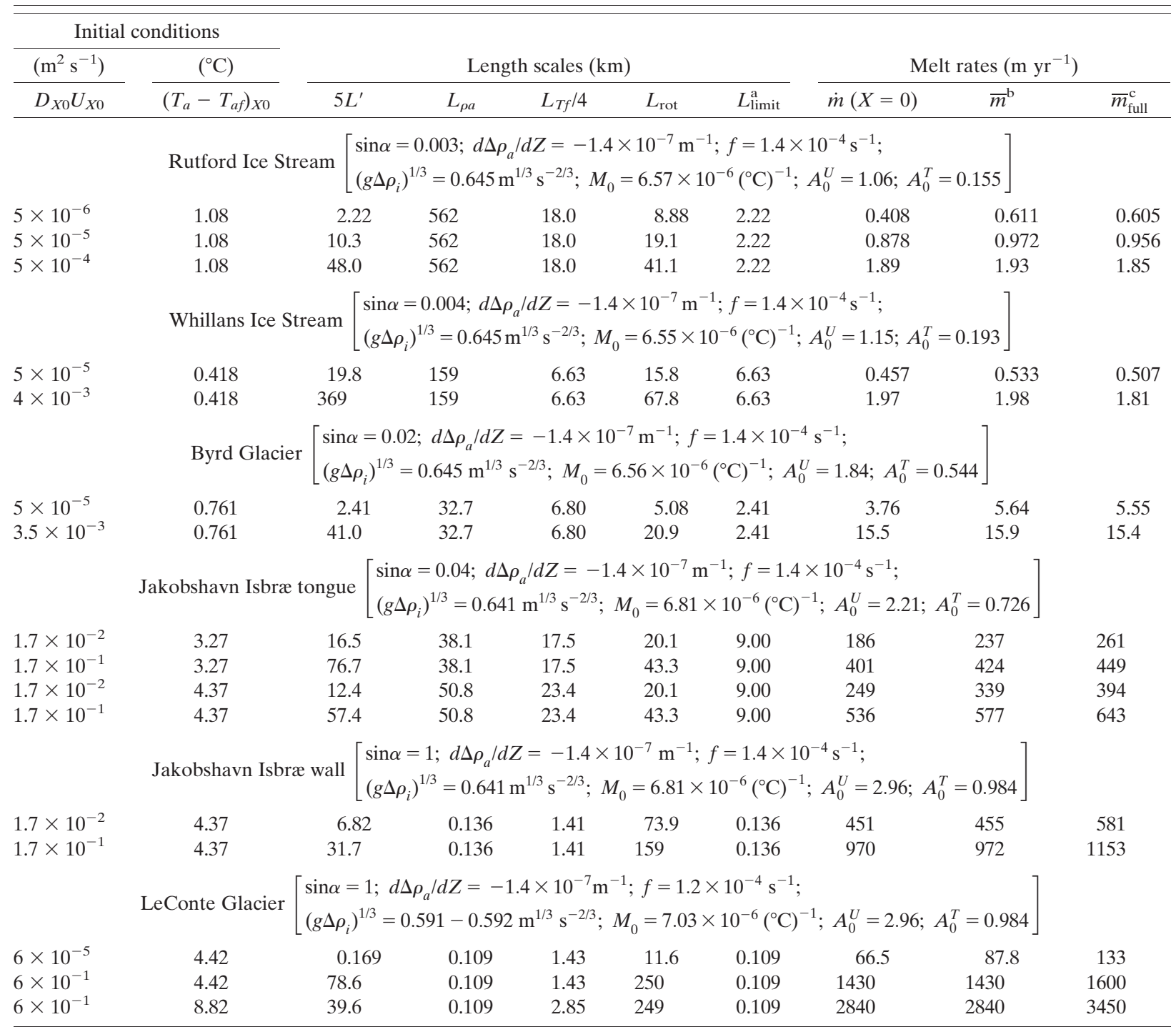

${ }^{a}$ Effective limit of model validity set by the smallest length scale or the length of the ice-ocean interface if that is shorter.

${ }^{\mathrm{b}}$ Mean melt rate derived from Eq. (40) over the region between $X=0$ and $X=L_{\text {limit }}$.

${ }^{\mathrm{c}}$ Mean melt rate derived from Eqs. (1)-(9) over the region between $X=0$ and $X=L_{\text {limit }}$.

Rutford Ice Stream. The change of the freezing point with depth limits the applicability of the reduced model to slightly less than $7 \mathrm{~km}$. The drainage of a subglacial lake across the grounding line, reported by Fricker et al. (2007), represented a significant perturbation to the background flow. At peak discharge, the flux of freshwater was two orders of magnitude above the background flow, implying an approximate fourfold increase in the mean melt rate.

\section{c. Byrd Glacier}

Stearns et al. (2008) observed the discharge of a subglacial lake beneath the upper part of Byrd Glacier. Although the lake was some distance from the grounding line, they inferred from the increase in flow speed of the glacier that the water drained toward the ice shelf. Most parameters for the glacier and the outburst flood are similar to those used for Whillans Ice Stream. The exception is the much higher slope of the ice shelf base that leads to background melting an order of magnitude higher. In terms of the melt rate sensitivity, the impact of the flood is very similar. The two orders of magnitude increase in the freshwater flux gives a quadrupling of the melt rate at the grounding line and a tripling of the mean melt rate over the region of applicability of the reduced model. In this case, the small size of the background buoyancy flux limits the zone to a few kilometers. 


\section{d. Jakobshavn Isbrae}

Jakobshavn Isbræ is one of the better studied of the large Greenland outlet glaciers, although there are only limited oceanographic observations from within the fjord into which it drains. The standard value for the ambient seawater stratification is used, whereas temperatures within the fjord are assumed to be $1^{\circ} \mathrm{C}$ cooler than those observed outside (D. M. Holland et al. 2008). Significant quantities of meltwater are thought to be generated at the glacier bed, and these are supplemented by surface meltwater in the summer giving an order of magnitude change in the freshwater flux at the grounding line (Echelmeyer and Harrison 1990). This implies a peak summer melt rate that is about twice the wintertime minimum, irrespective of any seasonal changes in the fjord temperature (cf. any pair of rows in Table 4 with low/high initial freshwater flux but the same temperature). Prior to the most recent retreat of the calving front that began in 1997, the floating tongue was about $9 \mathrm{~km}$ long (Motyka et al. 2011), a distance over which the reduced model is always valid (so $L_{\text {limit }}=9$ in Table 4 ). It has been proposed that the 1997 retreat was precipitated by an increase in the fjord water temperature of around $1^{\circ} \mathrm{C}$ (D. M. Holland et al. 2008; Motyka et al. 2011). Such a change in temperature could have increased the melt rates by about a third (cf. the two pairs of rows in Table 4 with low/high temperature but the same initial freshwater flux and glacier extent). If the tongue were formerly in equilibrium with the seasonally varying melt rate, such an increase in melting would have caused a seasonally varying thinning rate ranging from 100 to $150 \mathrm{~m} \mathrm{yr}^{-1}$. Following the retreat, it is thought that there is little left of the floating tongue so that the glacier terminates in a near-vertical calving face with a draft of around $900 \mathrm{~m}$ (Motyka et al. 2011). The impact of the change in slope of the ice-ocean interface is a near doubling of the melt rate (cf. the two pairs of rows in Table 4 with differing interface slope but the same temperature and initial freshwater flux), with the factor of 2 between summertime maximum and wintertime minimum remaining unaltered. Stratification now limits the applicability of the reduced model to the first $136 \mathrm{~m}$ of the plume's ascent. Using the full model, the far-field behavior of the plume can be investigated. With this admittedly arbitrary choice of ambient stratification, the plume can only reach the surface in summer, becoming neutrally buoyant about $100 \mathrm{~m}$ below the surface in winter.

\section{e. LeConte Glacier}

LeConte Glacier is a temperate Alaskan glacier that terminates in a vertical calving face having a mean draft of approximately $200 \mathrm{~m}$. The discharge of subglacial meltwater is estimated by Motyka et al. (2003) to vary from low levels in winter to around $435 \mathrm{~m}^{3} \mathrm{~s}^{-1}$ in summer, whereas water temperatures in LeConte Bay vary by at least $4^{\circ} \mathrm{C}$ through the year. Once again, the arbitrary stratification limits the validity of the reduced model to the lower half of the calving face. Results suggest that the estimated four orders of magnitude change in the freshwater discharge drives a factor of 15-20 increase in the melting (cf. the first and second rows in Table 4), whereas the change in fjord temperature gives a further doubling (cf. the second and third rows in Table 4). The simulated summertime peak in melting is still smaller than that estimated by Motyka et al. (2003), but the model clearly demonstrates the dramatic impact of the subglacial stream on convection-driven melting of the calving face. The relatively large differences between the reduced and full models are a consequence of using Eqs. (7)-(9) in the full model versus (10) and (11) in the reduced model.

\section{Summary and conclusions}

The theory of inclined plumes has provided much insight into the processes of ocean circulation and melting beneath ice shelves since its first application to the problem by MacAyeal (1985). The main focus of that and subsequent studies has been the large-scale, buoyancy-driven circulation and the phase changes that are both the origin and the consequence of the water motion. Although more complex three-dimensional ocean general circulation models are now in common use for studies of these processes, plume theory can still provide important insight over smaller spatial scales. Because the hydrostatic approximation is typically applied along a coordinate axis that is normal to the ice-ocean interface, rather than along the local vertical, plume theory is particularly good at capturing processes taking place alongside very steep or even vertical interfaces.

In this paper, plume theory has been applied to the zone very close to the grounding line, where the flow of freshwater that initiates the plume remains the dominant source of buoyancy. The same equations [(1)-(4), (14)(17), or (27)-(30)] can be applied within and without this zone, with the scaled versions [(27)-(30)] merely emphasizing the closer correspondence with conventional plume equations within the initial zone. Indeed, with $\delta T_{a}=0$ and $l_{T f}=\infty$ in the scaled equations, $\delta T=0 \mathrm{ev}-$ erywhere and the only source of buoyancy is that at the origin. Equations (27)-(30) then have solutions of the same form as those discussed by Morton et al. (1956).

The model presented here unifies the concept of convection-driven melting, described by Motyka et al. (2003), with the more general concept of melt-driven convection beneath ice shelves. The only distinction 
between the two is whether the primary source of buoyancy is input at the origin or generated by the subsequent flow of the resulting plume. Generally, there will be a smooth transition between the two regimes. If the development of the plume is limited by the physical size of the domain, the strength of the ambient stratification or the low level of the ambient temperature, convectiondriven melting can be the dominant process, and it will always dominate within a sufficiently small region immediately downstream of the grounding line. The aim of this study has been to quantify the size of that region and the melt rate within it.

The main conclusion to be drawn is that freshwater drainage beneath outlet glaciers and its variability will have a major impact on melting at and immediately downstream of the grounding line. Within this region, the melt rate scales with the cube root of the freshwater flux, implying slightly more than a doubling of the melt rate for an order of magnitude increase in flux. Beyond the region of convection-driven melting, the sensitivity of the melt rate to the freshwater flux falls as the initial flux makes an ever-smaller contribution to the total buoyancy of the plume. Melting is, however, less sensitive to the ambient ocean temperature within the region of convectiondriven melting than beyond it. In both cases the plume temperature rises approximately linearly with the ambient temperature (P. R. Holland et al. 2008). However, in the zone of melt-driven convection the plume velocity is also a function of plume temperature (P. R. Holland et al. 2008), because melting at the ice-ocean interface is the dominant source of buoyancy, whereas in the zone of convection-driven melting the plume velocity is independent of plume temperature, because melting has, by definition, a negligible impact on plume buoyancy. Hence, the melt rate, which depends on the product of plume velocity and temperature, rises linearly with ambient temperature for convection-driven melting (Fig. 8) but nonlinearly for melt-driven convection.

The sensitivity of melting near a grounding line to the discharge of subglacial meltwater has important implications. The drainage of a subglacial lake across a grounding line can increase the melt rate there by many meters per year. Where surface meltwater reaches the bed of a glacier and drains across the grounding line, the result will be a summertime peak in melting near the grounding line, regardless of any seasonality in the ambient seawater temperature. An increase in the volume of meltwater produced in the summer, as has been observed in recent years on the Greenland Ice Sheet (Bhattacharya et al. 2009; van den Broeke et al. 2010), will cause an increase in the summertime peak in melting near the grounding line and is a potential contributing factor in the retreat of tidewater glacier termini. If the freshwater outflows are localized in space, as a result of a channelized subglacial drainage network, the outflow will generate incised channels in the base of the ice shelf or the calving face of the tidewater glacier, because melting will be more rapid along the path of the plume than elsewhere. Such a process is a potential origin of some of the cross-stream thickness variability often observed near grounding lines (Rignot and Steffen 2008; Motyka et al. 2011) and is a particularly strong candidate for producing along-stream variability in the structure of channels. For example, an outburst flood from a subglacial lake would produce an isolated channel that would subsequently decay in amplitude as it was advected downstream by the ice shelf flow. Finally, there is a potential role for freshwater discharge in driving the motion of grounding lines. Unlike changes in ocean temperature that can only perturb the melt rate downstream of the grounding line, a change in the flow of water beneath an outlet glacier can change the basal melt rate and hence cause changes in ice thickness upstream of, at, and downstream of the grounding line.

Acknowledgments. The author is grateful for the detailed and constructive comments of an anonymous reviewer on an earlier draft of this paper.

\section{REFERENCES}

Beckmann, A., H. Hellmer, and R. Timmermann, 1999: A numerical model of the Weddell Sea: Large-scale circulation and water mass distribution. J. Geophys. Res., 104, 23 375-23 391.

Bhattacharya, I., K. C. Jezek, L. Wang, and H. Liu, 2009: Surface melt area variability of the Greenland Ice Sheet: 1979-2008. Geophys. Res. Lett., 36, L20502, doi:10.1029/2009GL039798.

Chu, V. W., L. C. Smith, A. K. Rennermalm, R. R. Forster, J. E. Box, and N. Reeh, 2009: Sediment plume response to surface melting and supraglacial lake drainages on the Greenland Ice Sheet. J. Glaciol., 55, 1072-1082.

Das, S. B., I. Joughin, M. D. Behn, I. M. Howat, M. A. King, D. Lizarralde, and M. P. Bhatia, 2008: Fracture propagation to the base of the Greenland Ice Sheet during supraglacial lake drainage. Science, 320, 778-781, doi:10.1126/science.1153360.

Echelmeyer, E. C., and W. D. Harrison, 1990: Jakobshavn Isbræ, west Greenland: Seasonal variations in velocity-Or lack thereof. J. Glaciol., 36, 82-88.

Ellison, T. H., and J. S. Turner, 1959: Turbulent entrainment in stratified flows. J. Fluid Mech., 6, 423-448.

Fernando, H. J. S., and C. Y. Ching, 1993: Effects of background rotation on turbulent line plumes. J. Phys. Oceanogr., 23, 2125-2129.

Fricker, H. A., T. Scambos, R. Bindschadler, and L. Padman, 2007: An active subglacial water system in West Antarctica mapped from space. Science, 315, 1544-1548, doi:10.1126/ science. 1136897.

Grosfeld, K., R. Gerdes, and J. Determann, 1997: Thermohaline circulation and interaction between ice shelf cavities and the adjacent open ocean. J. Geophys. Res., 102, 15 595-15 610. 
Hellmer, H. H., and D. J. Olbers, 1989: A two-dimensional model for the thermohaline circulation under an ice shelf. Antarct. Sci., 1, 325-336.

Holland, D. M., and A. Jenkins, 1999: Modeling thermodynamic ice-ocean interactions at the base of an ice shelf. J. Phys. Oceanogr., 29, 1787-1800.

—, R. H. Thomas, B. de Young, M. H. Ribergaard, and B. Lyberth, 2008: Acceleration of Jakobshavn Isbræ triggered by warm subsurface ocean waters. Nat. Geosci., 1, 659-664, doi:10.1038/ngeo316.

Holland, P. R., A. Jenkins, and D. M. Holland, 2008: The response of ice shelf basal melting to variations in ocean temperature. J. Climate, 21, 2558-2572.

Hughes, T., 1973: Is the West Antarctic Ice Sheet disintegrating? J. Geophys. Res., 78, 7884-7910.

Jenkins, A., 1991: A one-dimensional model of ice shelf-ocean interaction. J. Geophys. Res., 96, 20 671-20 677.

—_, and C. S. M. Doake, 1991: Ice-ocean interaction on Ronne Ice Shelf, Antarctica. J. Geophys. Res., 96, 791-813.

_- and D. M. Holland, 2002: A model study of ocean circulation beneath Filchner-Ronne Ice Shelf, Antarctica: Implications for bottom water formation. Geophys. Res. Lett., 29, 1193, doi:10.1029/2001GL014589.

— Geophys. Res. Lett., 34, L16609, doi:10.1029/2007GL030784.

- H. H. Hellmer, and D. M. Holland, 2001: The role of meltwater advection in the formulation of conservative boundary conditions at an ice-ocean interface. J. Phys. Oceanogr., 31, 285-296.

— H. F. J. Corr, K. W. Nicholls, C. L. Stewart, and C. S. M. Doake, 2006: Interactions between ice and ocean observed with phase-sensitive radar near an Antarctic ice shelf grounding line. J. Glaciol., 52, 325-346.

—, K. W. Nicholls, and H. F. J. Corr, 2010: Observation and parameterization of ablation at the base of Ronne Ice Shelf, Antarctica. J. Phys. Oceanogr., 40, 2298-2312.

Joughin, I., and L. Padman, 2003: Melting and freezing beneath Filchner-Ronne Ice Shelf, Antarctica. Geophys. Res. Lett., 30, 1477, doi:10.1029/2003GL016941.

_ - E. Rignot, C. E. Rosanova, B. K. Lucchitta, and J. Bohlander, 2003: Timing of recent accelerations of Pine Island Glacier, Antarctica. Geophys. Res. Lett., 30, 1706, doi:10.1029/2003GL017609.

_- W. Abdalati, and M. Fahnestock, 2004: Large fluctuations in speed on Greenland's Jakobshavn Isbræ glacier. Nature, 432, 608-610, doi:10.1038/nature03130.

—, S. B. Das, M. A. King, B. E. Smith, I. M. Howat, and T. Moon, 2008: Seasonal speedup along the western flank of the Greenland Ice Sheet. Science, 320, 781-783, doi:10.1126/science. 1153288.

Kader, B. A., and A. M. Yaglom, 1972: Heat and mass transfer laws for fully turbulent wall flows. Int. J. Heat Mass Transfer, 15, 2329-2351.

— , and - 1977: Turbulent heat and mass transfer from a wall with parallel roughness ridges. Int. J. Heat Mass Transfer, 20, 345-357.

MacAyeal, D. R., 1985: Evolution of tidally triggered meltwater plumes below ice shelves. Oceanology of the Antarctic Continental Shelf, S. S. Jacobs, Ed., Antarctic Research Series, Vol. 43, Amer. Geophys. Union, 133-143.
McPhee, M. G., 1992: Turbulent heat flux in the upper ocean under sea ice. J. Geophys. Res., 97, 5365-5379.

_ 1994: On the turbulent mixing length in the oceanic boundary layer. J. Phys. Oceanogr., 24, 2014-2031.

— C. Kottmeier, and J. H. Morison, 1999: Ocean heat flux in the central Weddell Sea during winter. J. Phys. Oceanogr., 29, 1166-1179.

Morton, B. R., G. Taylor, and J. S. Turner, 1956: Turbulent gravitational convection from maintained and instantaneous sources. Proc. Roy. Soc. London, 234A, 1-23.

Motyka, R. J., L. Hunter, K. A. Echelmeyer, and C. Connor, 2003: Submarine melting at the terminus of a temperate tidewater glacier, LeConte Glacier, Alaska, U.S.A. Ann. Glaciol., 36, 57-65.

—, M. Truffer, M. Fahnestock, J. Mortensen, S. Rysgaard, and I. Howat, 2011: Submarine melting of the 1985 Jakobshavn Isbræ floating tongue and the triggering of the current retreat. J. Geophys. Res., 116, F01007, doi:10.1029/2009JF001632.

Pollard, D., and R. M. DeConto, 2009: Modelling West Antarctic Ice Sheet growth and collapse through the past five million years. Nature, 458, 329-332, doi:10.1038/nature07809.

Rignot, E. J., 1998: Fast recession of a West Antarctic glacier. Science, 281, 549-551, doi:10.1126/science.281.5376.549.

_- 2008: Changes in West Antarctic ice stream dynamics observed with ALOS PALSAR data. Geophys. Res. Lett., 35, L12505, doi:10.1029/2008GL033365.

_ near Antarctic ice sheet grounding lines. Science, 296, 20202023, doi:10.1126/science.1070942.

_- and K. Steffen, 2008: Channelized bottom melting and stability of floating ice shelves. Geophys. Res. Lett., 35, L02503, doi:10.1029/2007GL031765.

Schoof, C., 2007: Ice sheet grounding line dynamics: Steady states, stability and hysteresis. J. Geophys. Res., 112, F03S28, doi:10.1029/2006JF000664.

Shepherd, A., D. Wingham, and E. Rignot, 2004: Warm ocean is eroding West Antarctic Ice Sheet. Geophys. Res. Lett., 31, L23402, doi:10.1029/2004GL021106.

Smith, B. E., H. A. Fricker, I. R. Joughin, and S. Tulaczyk, 2009: An inventory of active subglacial lakes in Antarctica detected by ICESat (2003-2008). J. Glaciol., 55, 573-595.

Stearns, L. A., B. E. Smith, and G. S. Hamilton, 2008: Increased flow speed on a large east Antarctic outlet glacier caused by subglacial floods. Nat. Geosci., 1, 827-831, doi:10.1038/ngeo356.

van den Broeke, M., and Coauthors, 2010: Partitioning recent Greenland mass loss. Science, 326, 984-986, doi:10.1126/science. 1178176

Wells, A. J., and M. G. Worster, 2008: A geophysical-scale model of vertical natural convection boundary layers. J. Fluid Mech., 609, 111-137, doi:10.1017/S0022112008002346.

Wingham, D. J., D. W. Wallis, and A. Shepherd, 2009: Spatial and temporal evolution of Pine Island Glacier thinning, 1995-2006. Geophys. Res. Lett., 36, L17501, doi:10.1029/ 2009GL039126.

Zwally, H. J., W. Abdalati, T. Herring, K. Larson, J. Saba, and K. Steffen, 2002: Surface melt-induced acceleration of Greenland Ice-Sheet flow. Science, 297, 218-222, doi:10.1126/science. 1072708. 